\title{
Stress-Induced Recovery of Fears and Phobias
}

\author{
W. J. Jacobs \\ University of British Columbia \\ Vancouver, British Columbia, Canada
}

\author{
Lynn Nadel \\ School of Social Sciences \\ University of California at Irvine
}

\begin{abstract}
Accounts of human fears and phobias based on current conditioning models using data from adults are examined and found wanting. Instead, the characteristics of human phobias resemble the kind of learning found during the amnesic period of infancy. As certain neural systems mature, conditioning begins to exhibit adult characteristics: context dependency, sharp generalization, and rapid extinction. Although direct behavioral control by the early learning systems wanes, the adult learning system seems to be structured at least/partially through the lasting influence of infantile experience. Under (hormonal) stress, residues of early experience are reinstated and incorporated into adult memory where they directly control behavior. This control exhibits infantile characteristics. The evidence suggests that once acquired, such conditional fears might never be eliminated using traditional extinction or counterconditioning procedures. The view leads to a renewed emphasis upon the role of experience in human development, accepting the disproportionate importance of infant experience as the foundation upon which subsequent learning and cognitive function rest.
\end{abstract}

It is plain from clinical experience that certain patients experience critical incidents in which the fear has an onset. What is particularly interesting is the fact that quite frequently these same people have been exposed to the same stimulus repeatedly in the past without acquiring the fear. It seems that for acute onset fears, there are certain psychological states in which the person is vulnerable to the acquisition of fears. To take a clinical example, in those agoraphobic patients who report an acute onset of fear, one needs to know why the fear arose on the day that it did, at the time that it did. And why do they acquire a fear of public transport, crowded or open spaces, or whatever the content of their phobia, when on hundreds or thousands

The first author acknowledges the fundamental contributions of David Furrow, Scon Mendelson, Michael Buttrick. Dennis Paul, Jim Pfaus, Trish, Duncan Kennedy, Shayne Kardal, Vin LoLordo, Fred Madryga, Bob Bolles, Don Wilkic, John Pinel. and Guy Andrew Vaz. These colleagues and associates provided ideas, support, and encouragement throughout.

Preparation of this article was supported in part by NSERC (National Science and Research Council) University Research Fellowship U0262 awarded to the first author.

The second author acknowledges his debts to all who have ever thought about the hippocampus, cognitive maps, or space, and to support from NINCDS (National Institute of Neurological and Communication Disorders and Stroke) Grant NS 17711 and March of Dimes Birth Defects Foundation Grant 12-143.

Requests for reprints should be sent to W. J. Jacobs. Department of Psychology. 2075 Wcsbrook Mall. University of British Columbia, Vancouver, British Columbia. Canada V6T 1W5, or to Lynn Nadel, now at the Department of Psychology, University of Arizona, Tuscon. Arizona 85721. of previous exposures to the same set of stimuli, they remained unaffected? (Rachman. 1977, p. 385)

\section{Problems}

Imagine yourself in a clinical situation, scheduled to conduct two intake interviews. Your first client is a well-dressed, articulate woman. She appears calm and answers your questions completely and clearly. She describes a successful business career, an apparently enjoyable marriage, the recent birth of her first child, an active social life with interests in dance, music, and modem art. The problem that has brought her to the clinic is a fear of insects and bugs in general. Even though she has never liked bugs, never before have they influenced her social or business life. Soonafter the birth of hen-child, she developed fears that began to grow into a terror of crawling or flying insects. She has begun to feel uncomfortable in her office and in her home. She regularly inspects her desk and office for the presence of insects. She is afraid to sleep at night because she found a small bug on her bed covers 3 weeks ago. Her housekeeper of 11 years was dismissed because of the incident. All of this seems quite out of character for her. As she continues to talk about the problem, she becomes irritable and less communicative. On further questioning you find that her fears have 
begun to interfere with her marriage, her career, and her maternal life. As a first step in treatment, you recommend relaxation training and systematic desensitization of the insect phobia, coupled with a cognitive behaviormodification program, designed to improve her confidence and competence in social situations.

Your second client is familiar. You saw him years ago. At that time you had successfully treated a fear of heights. He explains that his family was involved in an air accident 4 months earlier. He. lost his wife and his only son in the accident. He was injured only slightly, but his sorrow from the loss almost completely overwhelmed him. He felt out of touch with his business associates, remaining family, and friends. He had trouble sleeping, thinking clearly, and interacting in his office. As time passed, this intense emotional reaction diminished somewhat and he regained contact with his family and business associates. Even so. he is still somewhat troubled. In addition, his height phobia and several related fears have reappeared. This, he explains, is understandable because of the circumstances of his wife's and son's deaths. Because his office building is a windowed high-rise, fear is once again interfering with his business life. After an extensive interview, you suggest supportive therapy, coupled with relaxation retraining aimed at eliminating the height phobia. He seems satisfied with this arrangement, makes his next appointment, and leaves.

\section{Approaches}

Two major paradigmatic approaches have been applied to the analysis and treatment pf problems of this nature. Although both approaches emphasize the role of learning in the development of these problems, they differ in the emphasis that is placed upon the ontogenetic timing of this experience. The first approach invokes what may be called the tyranny of childhood. In general, it suggests that early learning or genetic factors present at birth have a profound (and disproportionate) influence upon the personality and behavior of the adult individual. This approach receives some support from the experimental laboratory (e.g., Gottlieb, 1976), from naturalistic work (e.g., Marler, 1977), and from clinical observations (e.g., Freud, 1895). Currently available treatments based upon this paradigm advocate a resurrection and resolution of early childhood conflicts. The second major approach is based upon behavioral learning theory. In general, this approach suggests that virtually all behaviors and personality characteristics are acquired during the life history of the individual. Here the laws of Pavlovian conditioning and operand learning are in action throughout life, continuously modifying and shaping both emotional life and overt behavior. Currently available treatments that are based upon this approach advocate a change in reinforcement contingencies (including cognitive behavior modification) or highly specific counterconditioning procedures to attack an extant emotional or behavioral problem.

Although both approaches have been roundly criticized (e.g.. Bergin, 1963; Breger \& McGaugh, 1965: Evsenck, 1976, 1979, 1981; Locke, 1971; Rachman, 1976, 1977; Rachman \& Seligman, 1976; Rachmaii \& Wilson, 1980; Seligman, 1971) there exists a large experimental literature that seems to support the effectiveness of therapeutic techniques developed from learning-based models. This point is primary for those interested in delivering effective treatment. However, reliance upon technique alone fails to provide the clinician with a principled approach to any given psychopathological problem; one becomes eclectic, taking what appears to work in one case and applying it to other seemingly related cases. Without precise theoretical or practical guidance, this strategy too often flounders. It would be most satisfying to have a model that is both clinically useful and conceptually sound. The present article sketches out a preliminary statement of such a model and some of its implications.

\section{Features of Conditional Fears and Phobias}

We begin by extracting from our two examples features that seem to characterize the development of many human psychopathological problems. Several often-unremarked aspects of these problems are worthy of mention. First, as we question our clients, we note that they are often unable to report when and where the feared object or situation was specifically paired with a noxious event (see, e.g., 
Lazarus, 1971). If we are to maintain that a pairing of appropriate events is required for the acquisition of fear or anxiety, then it is necessary to postulate an additional process (e.g., a selective source amnesia for this critical pairing). Furthermore, individuals are often able to report the repeated occurrence of highly noxious events that do not result in the development of fear or anxiety (see Rachman, 1977). In this case it seems necessary to postulate a principled reason why phobias fail to result from such experiences. Second, these problems often simply appear following stressful but noncontingent events. In some cases, a mild fear is exacerbated following stress, but all too often a new and debilitating fear forms following severe stress or long-term illness (Rachman, 1977). This is quite unlike the conditions thought to produce associative learning. Third, once developed, the psychological difficulties manifest themselves with scant regard for any given environmental context. Anxiety or phobic reactions may strike at work. in an automobile, or even in the safety of one's own home. This runs counter to most known forms of learning. For example, Pavlovian fear conditioning appears to be largely context specific. A change in the context in which a conditional fear stimulus is presented can dramatically decrease both the intensity of the conditioned emotional response and the behavioral manifestation of that response (cf. Balaz. Capra, Harti, \& Miller, 1981; Balaz, Capra. Kasprow, \& Miller, 1982; Balsam \& Schwartz, 1981; Balsam \&. Tomie, 1985; Dweck \& Wagner, 1970; Gordon, McCracken, Dess-Beech, \& Mowrer. 1981; Marlin, 1981, 1982; Odling-Smee, 1975, 1978). Fourth, many human fears seem to generalize broadly, so broadly that in some cases (e.g., agoraphobia) the individual may not be able to tell us what is frightening. Fear may be directed toward all animate flying organisms, or all heights, or even simply going out of doors. In contrast, laboratory studies of conditional fear suggest that it is relatively stimulus specificthe generalization gradients typically obtained in these studies are not enough to account for the psychopathological manifestations seen in the clinic. Fifth, those afflicted with such problems often fail to show extinction after many years of exposure to the feared stimulus, even in the absence of any aversive conse- quences. Although the individual may "know" that the fear is irrational, strong emotional reactions continue to be exhibited to the objectionable stimulus or situation even after many exposures. This is at odds with the typical fearextinction pattern found in the laboratory: Pavlovian conditional fears are known to extinguish after relatively few unreinforced exposures (Mackintosh, 1974) and are quite sensitive to cognitive influences in humans (Grant. 1973; Grings, 1973).' Finally, the problems we described, although unusual, are not atypical; they are the kinds of phobias most often seen in the clinic. That is, the phobias that find their way to the clinic seem to fall into a narrow range of types (Marks, 1969). This runs counter to models that suggest that broadly based experience, and experience alone, determines the formation of human fear.

In short, learning-based models of human phobias and fears capture far too few features of the acquisition and retention of these problems: Acquisition seems to just happen, with no specific contingent pairings of the feared stimuli and aversive consequences; extinction is often quite prolonged; retention is manifested over a wide range of situations and with a broad range of similar stimuli; and the phobic "types" seen in the clinic differ in their distribution from those predicted by models emphasizing the central role of learning. None of these characteristics are predicted, by any known learning-based model.

\section{Infantile "Amnesia" and Two Learning Systems}

Focus for the moment on the fact that there seems to be no memory for appropriate conditioning events in many of these clinical cases. If we maintain that phobias are experientially based, then we must conclude that these failures of memory represent "amnesias" for the critical events. This requirement suggests that

' The reader must distinguish between Pavlovian fear conditioning and active avoidance training. There is evidence that active avoidance responding can be quite persistent during extinction; this is not the case with conditional fear (Mackintosh, 1974). In addition, active avoidance responding may persist in the absence of any delectable conditional fear measured either behaviorally or physiologically (see, e. g.. Black. 1959; Kamin, Brimer, \& Black, 1963; Linden, 1969; Mineka. 1979). 
we look carefully at learning that occurs early in life, a period during which the organism obviously experiences and learns, but which is not available to conscious report (Dudycha \& Dudycha, 1941; Moscovitch, 1984; Waldfogel, 1982). Few, if any memories of specific events from this stage of development are subsequently available to the adult. This "memory failure," known as infantile amnesia, is found not only in humans, but in other animals as well (cf. Spear \& Campbell, 1979). It is, we submit, central to the psychopathological phenomena under consideration.

There have been two broad classes of explanation for infantile amnesia. One asserts that the memories in question exist, but that they are inaccessible for one reason or another. The second states that, for biological reasons, the memories do not actually exist. Freud, who first discussed this phenomenon, held both positions at different times. Recent neurobiological evidence suggests that the correct view is closer to the second position.. That is, memories pertaining to certain aspects of early experience seem not to be available for purely biological reasons - the brain systems required for their elaboration do not fully mature until some years after birth. Other aspects of early memory are, however, intact, and it is these remnants, unconscious though they may be, that lay the basis for the profound effects of early experience upon subsequent behavior. We contend that these submerged (but not necessarily repressed) residues also provide the material from which pathological manifestations are later derived.

This is not an entirely new idea. Dollard and Miller (1950), in their attempt to integrate Freudian and Hullian concepts, sought an explanation for infantile amnesia in the preverbal and, hence, unconscious nature of early experience. Although we accept this emphasis on early experience, we focus less on the preverbal nature of early memories than on the absence of autobiographical detail. We suggest that this absence owes to the postnatal maturation of a specific neural system critical to the formation of memories with a personal content.

Recent studies of neuroanatomical development indicate that maturation proceeds postnatally in a number of brain systems including parts of the neocortex, cerebellum, and hippocampus. All of these have been implicated in various forms oflearning and memory (McCormick, Clark, Lavond, \& Thompson, 1982; Mishkin, Malamut, \& Bachevalier, 1984).

We focus on the hippocampal formation because this neural system has been implicated in precisely the forms of memory function that are apparently absent in infants. The hippocampal formation becomes functional only at, or some time after, the age of normal weaning. Although there are inadequate neuroanatomical data in humans, most observers agree that mature hippocampal function emerges some time after 18-36 months postpartum. Damage to this system in adults produces a relatively profound learning/memory impairment, which was once thought to cut across most boundaries (see, e.g., Milner, 1966). However, recent research with human and other mammalian species has made it clear that the defect is selective-what is most prominently lacking is the ability to form memories containing information about where and when events occurred. The absence of these autobiographical details following disruption of the hippocampal system in adults provides a close parallel to the normal state of affairs in infants, whose hippocampi have not yet matured. Nadel and Zola-Morgan (1984) gathered the now extensive data showing that considerable learning is possible prior to maturation of the hippocampal system, but that such learning does not include acquisition of information about the space/time context within which early experiences transpire.

Data such as these have led memory researchers to the notion that there are multiple forms of memory, each subserved by distinct neural subsystems displaying unique properties that reflect these systems in some way, and each demonstrating its own ontogenetic timetable. Recent developmental work with primates supports this notion (Bachevalier \& Mishkin, 1984). Although disagreementexists on the precise details of these systems, there is broad agreement that learning concerned with skills, rules, and procedures-ways of interpreting and acting upon the world-is separate from learning concerned with the time/space context of experience-the autobiographical details of an episode (cf. Bergson, 1896; Cohen \& Squire, 1980; O'Keefe \& Nadel. 1978; Reiff 
\& Scheerer, 1959; Ryle, 1949; Schacter \& Moscovitch, 1984; Squire, Cohen, \& Nadel, 1984).

This distinction between two different forms of learning, and the properties ascribed to each form, could help us to understand the peculiar properties of human fears and phobias. Consider these notions in terms of the specific dualmemory model proposed by 0 'K.eefe and Nadel (1978) on the basis of their research into hippocampal function. They suggest that the hippocampus serves a cognitive mapping function and is necessary for the internal representation, and subsequent recognition, of environments the organism has previously experienced (see also Nadel \& Willner, 1980; Nadel, Willner, \& Kurz, 1985). 0'K.eefe and Nadel draw a distinction between two types of learning systems, each realized within separate neuroanatomical regions. One is the cognitive mapping, or locale, system just noted. The other is the class oftaxon systems that are responsible for the acquisition of skills, rules, S-S (stimulus-stimulus) and S-R (stimulusresponse) bonds. ${ }^{2}$ Most important for the present analysis is the notion that context-specific memories flow out of the functioning of the locale system. Learning within the taxon systems is typically free of contextual constraint-a characteristic that resembles a basic, and hitherto unexplained, feature of human phobias.

0'K.eefe and Nadel (1978) described the kinds of information represented in these two systems in the following way:

Concepts and categories, the look, the feel and the sound of things, the goodness and badness of objects: All of these are represented in the taxon systems . . . what is missing is the spatio-temporal context in which this knowledge was acquired. . . this (spatio-temporal context) is provided by the locale system where representations from the taxon systems are located within a structure providing such a context, (p. 100)

Learning that goes on in the taxon systems uninfluenced by the locale system will not be tied to any given environmental context. Learning in these cases is unambiguous and manifests itself broadly_again, this matches what one sees in phobias. In contrast, learning that involves both taxon and locale systems will be context specific:

Since representations of events and objects in a laxon system do not incorporate spatial contexts, there may be confusion between contexts. Representations of a stimulus. encoded in terms of its spatial relationships to other stimuli, decreases confusability. An individual stimulus, occurring in different places, or in other environments, may have distinct, differentiable representations. Thus, objects (or events) are perceived as different, and may have different "meanings" In different contexts, (p. 95)

We may clarify the importance of the distinction between context-free and contextspecific learning by returning to our two examples. For the woman who is afraid of insects, the stimuli have an unambiguous meaning in all contexts: danger and fear. For the man. unencumbered by a phobia of this sort, insects have contextually defined meanings. A tarantula in a secure glass cage would cause no anxiety; the same spider on his shoulder would likely give him pause. Conversely, this man's fear of heights results in a cross-contextual fear of any situation involving heights. On the other hand, the woman, capable of responding to height in terms of the context in which it occurs, might even enjoy a secure but high windswept place. ${ }^{3}$

\footnotetext{
${ }^{2}$ These names were originally chosen to reflect (a) the concern of the locale system with spatial information and its maplike means of representing that information, and (b) the central role of all laxon systems in prototype or concept formation (O'Keefe \& Nadel, 1978).

${ }^{3}$ Traditionally, learning theory has denned the construct stimulus in physical terms. The construct has been identified with the physical measurement of it. The problem with this approach is that it fails to connect with the known neurophysiology of the sensory systems. As psychophysicisis have long known, the physical description of a stimulus may bear only a loose relation to what is going on in ihe central nervous system. Often, many physically different external stimuli will be processed into a single psychologically meaningful stimulus (sec Regan, 1982). Although we cannot develop this aspect of the current theoretical orientation here, we acknowledge its importance. Throughout this article, the term stimulus should be dinned as an internal event that bears some, but not total dependence on the external world. We do not expect a fear of spiders to be dependent on a direct pairing of the real world thing called spider, rather this fear could result from many separate pairings of the features that the stimulus complex called spider happens to contain, features thai are also contained in stimuli not identified as spider. In this way we suggest thai clinical problems such as agoraphobias and free-floating anxieties may be stimulus bound, but because the controlling stimulus features that elicit the anxiety occur in many different physically specified stimuli, the individual may not be able lo "know" what it is that is frightening. This suggests that in cases of agoraphobia and free-floating anxieties, psychophysical tests should be used to identify the channels or features that act to trigger the anxiety. Once these features are identified, standard methods of treatment may be applied.
} 
The position espoused by 0 'K.eefe and Nadel (1978) suggests that conditioning in adult organisms reflects contributions from both locale and taxon learning systems. At the earliest stages of conditioning in the adult, the locale system and its rapid acquisition of contextspecific information dominate behavior. With sufficient repetition and familiarity the taxon systems come into play, providing a basis for highly ritualized and stereotypic behaviors, yet the locale system remains available to react to new circumstances (Adams \& Dickinson, 1981; O'Keefe \& Nadel, 1978). Although the relevant features of phobias do not appear to follow the rules of conditioning observed in studies with adults, they do bear a strong resemblance to the kind of learning predicted to occur in the absence of the locale system, learning that occurs in young organisms prior to the full development of this late-maturing system. These considerations suggest that in order to experimentally examine those aspects of conditioning that relate directly to the clinic, it may be necessary to examine organisms without a fully functional hippocampus. This is possible through the comparative study of species in which the hippocampus does or does not exist (e.g., Devenport \& Holloway, 1980), through lesion studies in adults, ${ }^{4}$ and through the study of intact neonates.

Some striking parallels, and an interesting contrast, emerge when we compare the descriptive characteristics of human fears and phobias with the properties of fear conditioning instituted before the maturation of the locale system. Such neonatally conditioned responses generalize broadly (e.g., Gibson \& Gibson, 1955; Mednick \& Lehtinen, 1957; Reiss, 1946) and are context free. These are two of the more prominent features of the clinical syndrome. However, there is no parallel to the sudden, noncontingent emergence of fear. Furthermore, retention, rather than being unusually strong, is often poor in the neonate. It is our view that these apparently anomalous facts provide a foundation for the understanding of human phobias.

\section{Reinstatement: Steps Toward a Model of Human Phobias}

Conditional fear, established in infancy and subsequently forgotten, may be reinstated by hormonal or environmental manipulations. That is, the apparently lost effects of early experience may be made to suddenly reappear through subsequent stress. ${ }^{5}$ Riccio and Haroutunian (1979) outlined the results of their work on this phenomenon, which we consider in some detail. The data are consistent with the notion that fears, conditioned in the neonate prior to maturation of the hippocampal system, are available for return to the adult under stressful conditions. In the earliest studies. 21-day-old rats were given fear-conditioning trials. Virtually no retention was evidenced 2 weeks later-this is infantile amnesia (cf. Berk, Vigorito, \& Miller, 1979; Campbell \& Campbell, 1962; Campbell \& Jaynes. 1966; Campbell \& Spear, 1972; Coulter, Collier, \& Campbell, 1976; Spear, 1973; Spear \& Miller, 1981). In contrast to the behavior of these control animals, rats given an injection of epinephrine and exposed to the conditioned stimulus 1 week after conditioning, showed strong conditional fear a week after that. Subsequent work has shown such reinstatement after injections ofACTH and presentation of the conditioned stimulus 20 min later, and after presentations of the unconditional stimulus followed either $30 \mathrm{~s}$ or $20 \mathrm{~min}$ later by presentations of the conditioned stimulus. Tailshock, footshock, hypothermia, or even restraint can serve to reinstate a conditional fear that was established in infancy (Riccio \& Haroutunian, 1979; see also Spear \& Parsons, 1976).

Although the analysis of some of these studies is not without its problems, reinstatement is a phenomenon whose clinical implications are clear. Should it prove to depend on the

* Although we briefly mention lesion data, in this discussion we intentionally fail to consider their effects on the acquisition and extinction of conditional responding. Following lesions to this area, the hormonal system of the organism is changed in ways thai could functionally sensitize the taxon systems. From this point of view, acquisition or extinction effects that have been observed in classical conditioning following lesions do not necessarily reflect the normal sensitivity of taxon systems, but rather the sensitivity of the systems under extraordinary circumstances. Although these studies may provide valuable clues regarding our ability to manipulate taxon learning in highly stressful situations, they do not simply uncover laxon systems and allow us to directly examine them.

${ }^{3}$ Throughout this article, we define stress hormonally. Many different environmental complexes may elicit this hormonal state. 
pairing of conditional and unconditional stimuli during infancy, this fact, paired with infantile amnesia, would help us understand how phobias can both reflect learning and emerge suddenly without knowledge of their experiential origin. Exposure to stressful conditions appears to set the stage for the return of fear that was conditioned in infancy, but was apparently forgotten ${ }^{6}$ (see Squire, Cohen, \& Nadel, 1984, for a discussion of forgetting in the absence of the hippocampal system).

The question that is immediately apparent is this: Why does stress permit reinstatement to occur? We postulate that stress disrupts the function of the hippocampally based locale system and its context-specific learning capacities while potentiating taxon systems and their context-free associations.

There is considerable evidence that stress strongly influences hippocampal function. Animals react to stress with a range of adaptive behaviors, many of which are mediated by the release of hormones. Stress elicits the release ofACTH from the pituitary gland, which in turn stimulates the secretion of corticosterone (or cortisol) from the adrenal glands. There are corticosierone receptors distributed throughout the brain, but they are found most prominently in the hippocampus (McEwen, 1982: McEwen. Weiss. \& Schwartz, 1969: Sarrieau, Vial, Philbert. \& Rostene, 1984; Veldhuis, Van Koppen. Van Ittersum, \& de KJoet, 1982). Stress in adults has been shown to regulate the number of corticosterone receptors selectively in the hippocampus (and frontal cortex; Sapolsky, Krey, \& McEwen, 1984).

Although the mechanisms by which corticosterone exerts its effects remain uncertain, its ability to influence hippocampal functions through these receptors seems well established. Pfaff. Silva, \& Weiss (1971) showed that corticosterone diminished neural activity in the hippocampus, leading Micco, McEwen, and Shein (1979) to conclude that "hippocampal function may indeed be suppressed during periods of prolonged stress. . . this comes about through the suppressive influence oftransiently elevated plasma adrenal glucocorticoid (corticosterone) levels" (p. 328). Under these conditions, we submit, learning can occur that in many respects (i.e.. lack of context specificity) resembles learning seen in infancy. In this state, the occurrence of a conditional stimulus whose meaning was denned at an early age in an event long forgotten provides the trigger for a psychopathological reaction.

It is central to our model that early experience, although not behaviorally potent, leaves its mark upon the taxon circuits available to the young organism. Under severe stress behavioral control devolves on the taxon systems that are, in this state, unusually sensitive; any new learning, or releaming, that occurs during this period should be (relative to adults) quite robust. Once control has devolved on the taxon systems, retrieval or sudden releaming pertinent to these previously inaccessible residues of early experience becomes possible (Haroutunian \& Riccio, 1977, 1979a, 1979b).This, we assert, results because early experience has prepared those parts of the taxon learning systems representing conditional and unconditional stimuli, and those pathways mediating any associative connections between them. Given this early preparation, subsequent environmental contingencies may be highly degraded. and yet robust, long-lasting (re)leaming can still occur.

To briefly recapitulate; Our claim is that phobias and other pathological fears resemble the kind of learning seen in infancy, before the locale system is functional. They are triggered when stress disrupts the hippocampus and sets the stage for the formation of strong associations in taxon circuits already prepared by early experience with the relevant stimulus features.

This model rests upon the notions of stimulus representations and the preparation of circuits that must be more fully explicated. In what follows, we discuss data from a series of studies supporting the view that organisms form representations of stimuli and their relations. and that later experiences can influence these representations. Following that, we return to the question of prepared circuits and

\footnotetext{
${ }^{6}$ Indeed, Rachman (1977), in a discussion of the onset of agoraphobias, noted, "it seems likely that the critical incident occurs when the person is in an emotionally upset or apprehensive state ... Another predisposing factor seems to be physical illness and associated feelings of weakness, nausea, dizziness, etc." (p. 385; sec also Marks. 1969).

${ }^{7}$ Although we are suggesting that the hippocampus plays a central role in these processes, other brain areas must cenainlv be involved.
} 
some analysis of what the notion can be taken to mean.

\section{Representations}

What evidence have we that there is any such thing as a taxon system, representing stimuli, their "goodness and badness," and the like? What evidence do we have that these representations can be changed by subsequent experiences? Both of these are required by the model we are proposing. Strong evidence in support of this view comes from a study reported by Rescoria (1974), who showed that the strength of a conditional fear response could be dramatically increased simply by presenting a conditioned animal with intense noncontingent electric shocks. ${ }^{8}$ Rescoria suggested that this demonstration is consistent with the notion that conditioning may be viewed as "the construction of memories for individual events (such as the conditional and the unconditional stimuli) and the formation of associations between such memories . . . the observed conditioned response ... is a consequence oftheactivation of the US memory (p. 101)." Activation of the memory of the unconditional stimulus is mediated by a connection between elements representing the conditional stimulus and those representing the unconditional stimulus. Changing the memory of the unconditional stimulus directly changes the subsequent strength of the conditional response.

Several other studies confirm this picture of stimulus representations modifiable by experience. For example, Holland and Straub (1979) showed that conditioned responding that is based upon an appetitive unconditionaF stimulus is diminished if, after the conditional response is established, the affective value of the unconditional stimulus is changed by pairing it with poison. In addition, Rescoria (1973) has shown that habituating the unconditional stimulus (devaluing the memory of the stimulus) by repeatedly presenting it in isolation, results in the diminution of a previously established conditional fear (see also Holland \& Rescoria, 1975;Taylor, 1956). Sherman (1978) found these effects using trace conditioning and punishment procedures.

In an important extension of this theoretical work, Bouton (1982a, 1984) found that these inflation effects in adults, unlike most other learning effects, are context independent. Bouton conditioned a mild fear in separate groups of rats. Following conditioning, the rats in one group were given noncontingent presentations of intense electric shocks in the conditioning context; rats in another group received equivalent shock in a different context. When tested, all of the rats exhibited an increase in fear.

These studies indicate that changes in the representations of stimuli capable of leading to altered behavior can be brought about without direct pairing of the conditional and the unconditional stimuli.- Furthermore, such changes are independent of the context. Some of the manipulations (e.g., epinephrine or ACTH injections) require that the original conditional stimulus be re-presented while the organism is stressed (Riccio \& Haroutunian, 1979). Others (e.g., presentations of the original unconditional stimulus) will, in and of themselves, serve to reinstate a previously acquired fear (e.g., Bouton. 1984). All of these features parallel rather closely the development of fears and phobias in humans. They are properties of the taxon systems.

\section{Preparation of Circuits}

In the clinic, one sees many more fears of spiders, snakes, and heights than of electric sockets, knives, and plants. This is true even though spiders, snakes, heights, electric sockets, and plants may be equally dangerous during the ontogenetic history of an individual (seeGeer, 1965;Landy\&Gaupp. 197I;Lawlis, 1971; Marks, 1969; Rubin, Ka.tkin, Weiss, \& Efran, 1968; Seligman, 1971: Wolpe \& Lang, 1964). Seligman (1971) suggested that these fears are based upon phylogenetically "prepared" associations that may be formed even with highly degraded input.

'The.rulcs that we outline here apply only lo first-order conditional responding. A different set of rules apply to second-order conditional responding (see Rescoria, 1980).

' The only known exception to the general rule that manipulation of the strength of the unconditional stimulus after conditioning results in a change of the strength of the conditional response occurs in conditioned taste aversions (see Bouton, 1982b; Jacobs, Zeiner, Rjley, \& LoLordo, 1981; Riley. Jacobs, \& LoLordo, 1976). 
This assertion is consistent with a substantial amount of experimental data. For example, Garcia and Koelling (1966) reported that rats easily learn to passively avoid the taste of food if that taste is followed with illness. If the taste is followed by electric shock, the rats give no sign of fearing or avoiding the taste. Conversely, rats learn to fear and passively avoid the sight of food or an auditory stimulus more easily with shock than with illness. In a similar vein, Foree \& LoLordo $(1973,1975)$ reported that pigeons are able to associate visual stimuli with food but apparently not with a painful stimulus. The same birds associate an auditory stimulus with pain but apparently not with food. Finally, Jacobs and LoLordo (1977, 1980) reported that rats can easily associate auditory stimuli with pain but not with safety. The same rats easily associate a visual stimulus with safety but not with pain. Thus, it appears that certain combinations of conditional and unconditional stimuli in adult organisms produce rapid learning, and other combinations produce little or no learning at all. Learning systems seem to be structured in such a way that they are sensitive to some stimulus combinations and not to others. This observation has led many to suggest that the organism comes to the world prepared to form certain associations (Domjan \& Galef, 1983; Jacobs \& LoLordo, 1977. 1980; LoLordo, 1979; LoLordo \& Jacobs, 1983; Seligman, 1970: Shettleworth, 1972. 1979, 1983).

Attempts to integrate this view into learning theory have typically relied on the evolutionary significance of stimuli in the phylogenetic history of the organism under study. It is assumed that selective pressure has been exerted on learning systems, rendering them particularly sensitive to some, but not all, contiguous relations among stimuli. This general view provides an apparently powerful explanation of the experimental demonstrations of prepared associations and may help us to understand the unusual distributions of fears and phobias found in the clinical population. Furthermore, it could afford specific guidance in the treatment of human fears and phobias. Properly developed, it should predict the ease with which a phobia is acquired, the severity of the impairment that will be produced by phobias with a given content, and the ease with which a phobia may be eliminated.
Unfortunately, there is a growing list of problems with this theoretical orientation (in its purest form) both in the clinical and in the experimental literature. Consider the work of Ohman and his colleagues (e.g., Fredrikson, Hugdahl, \& Ohman, 1977; Hugdahl, Fredrikson, \& Ohman, 1977; Hugdahl \& Ohman, 1977; Ohman, Eriksson, \& Olofsson; 1975; Ohman, Erixon, \& Lofberg, 1975; Ohman, Fredrikson, Hugdahl, \& Rimmo, 1976). In humans, pictures of snakes or spiders paired with electric shock produce learning that is both rapid and quite resistant to extinction. Pictures of flowers or mushrooms paired with shock usually produce learning that is both slow and relatively easy to extinguish. These data were interpreted in terms of Seligman's notion of preparedness: We humans are prepared to associate aversive consequences with snakes and spiders but not with flowers and mushrooms. However, there are reasons to doubt this interpretation. As Delprato (1980) has forcefully pointed out, it is not an easy matter to determine in advance which stimuli should be thought of as biologically prepared and which as neutral.

Beyond such problems of circularity of the notion of preparedness, as defined earlier, there are clinical data indicating that this theoretical orientation fails to account for or to predict (a) the outcome of therapy, (b) the most efficacious therapeutic approach, (c) the severity of the impairment, (d) the extent of therapy required to relieve the phobic reaction, (e) the suddenness of phobic onset, or (f) the age of phobic onset (DeSilva, Rachman \& Seligman, 1977; see also McNally \& Reiss, 1982). Furthermore, phobic reactions to stimuli that do not seem to be biologically significant (e.g., the color brown, or string, or chocolate) share onset characteristics, resistance to treatment, severity. and duration features with phobic reactions to stimuli that do seem to be biologically significant (e.g., the dark, animals, or heights; see Rachman \& Seligman, 1976).

In addition, a growing body of experimental literature indicates that the strongest versions of biologically or genetically based theories are somewhat in error. Although we do not doubt the claim that there are phylogenetically prepared neural circuits, there may be rather fewer of these than was previously thought. Thus, Krane and Wagner(1975) reported that under 
some circumstances an association between taste and electric shock can be formed. Willner (1978) and others (e.g.. Archer, Sjoden, \& Nilsson, 1985;Dalrymple\&Galef, 1981;Galef \& Dalrymple, 1981) have shown that associations may be formed between exteroceptive stimuli and illness by rats. LoLordo, Jacobs, and Foree (1982) reported that pigeons are able to associate tones with food reward and light presentations with electric shock. We formerly thought that these associations are more difficult to form than they appear to be (see also Shapiro, Jacobs, \& LoLordo, 1980; Shapiro \& LoLordo, 1982). Moreover, Holland (1977) reported data that show that the modality of the conditional stimulus will strongly influence iheform of the conditional response. This suggests that experimenters who measure a single response in a learning experiment may erroneously conclude that they are examining a constrained learning system, when in fact they are simply failing to measure the learning that does occur (see. e.g., Revusky \& Parker, 1976; Rudy, Iwens, \& Best. 1977; Rudy, Rosenburg, \& SandelL 1977: Shettleworth. 1972, 1979, 1983; Wilkie \& Masson, 1976).

Although these data cast some doubt upon the validity of theories using the strongest form of the adaptive-evolutionary argument, we are still faced with the problem of explaining the fact of structured (constrained) learning systems in adults and the nonuniform distribution of human fears and phobias. If learning systems are not completely prepared by phylogeny, how can we account for these phenomena? Mackintosh (1973, 1974, 1983) proposed that variations in associability between different combinations of conditional and unconditional stimuli reflect earlier learning about the extent to which these, or similar, stimuli co-occurred. If an organism learns during ontogeny that certain classes of stimuli go together, then stimuli belonging to these classes might subsequently be subject to rapid conditioning- In contrast, if the organism learns thai certain classes of stimuli are unrelated, then stimuli belonging to these classes might subsequently be difficult to associate. By this account, the rate at which associations are formed during any learning experience is determined by savings from earlier experience (Bandura, 1977; Testa \& Temes, 1977; see also Baker, 1976; Baker \& Mackintosh, 1977, 1979;
Kremer, .1971; Randich \& LoLordo. 1979; Randich \& Haggard, 1983:Tomie, 1976, 1981; Tomie, Murphy, \& Fath. 1980; Wickins, Tuber, \&. Wickens, 1983). If context-free associative learning such as this occurs in the infant, it may serve as an associative base upon which subsequent learning (and higher level cognitive programs) is dependent.

It is known that early experience influences both neural development and adult behavior. Specific experiences help determine the tuning curves of cells in the visual cortex (Blakemore, 1974) and the auditory system (Clopton \& Winfield, 1976). Experience affects whether visual cells will be driven through one eye or through both (Hubel \& Wiesel, 1965). In humans, exposure to the limited number of features found in the native language early in life limits the features that may be perceived or recognized later in life (Mivawaki et al. 1975: Tees \& Werker, 1981; Werker, Gilbert, Humphries, \& Tees, 1981). In the sparrow, early exposure to songs of their own species determines the form and the dialect of the song produced in adult life (e.g., Marler, 1970; Marler, Mundinger, Waser, \& Lutton, 1972; Marler \& Peters, 1981). In "whydah birds ( $V i$ duinae\}. . . essential pans of the adult bird's song (are) learned by monitoring the begging tones and other tonal expression of whichever species of host bird the whydah happened to be hatched and reared" (Lorenz, 1981, p. 10). In rats, the taste of foods eaten by the mother and passed through her milk determines the dietary preferences of her infants in later life (Galef\& Sherry, 1973). In macaques, exposure to active mothering and normal social experience determines the quality of future sexual, social, and maternal behavior (e.g., Harlow \& Mears, 1979).

Even though dramatic, these demonstrations of the effects of early experience fall somewhat short of the kinds of changes required by the model we have spelled out. We suggested that under stressful conditions a pecular learning situation arises. Context-free associations, robust and difficult to extinguish, can form within circuits prepared during early life. Until recently, there has been no direct evidence of early experience preparing associative networks in this way. In her doctoral thesis, Sullivan (1979) provided data relevant to this point. She noted first that the experience 
of the average laboratory rat, combined with the ability to learn to attend to relevant cues and to ignore irrelevant ones, could account for the apparent constraints in taste-aversion studies. Laboratory rats experience little variability in their diets. They eat the same thing most of the time, and the visual features of the food are completely unrelated to its gustatory consequences.

If we assume that for the rat (a) a taste quality is the best predictor of the effects of ingeslion, (b) an individual is capable of learning this relationship, and (c) this information influences subsequent formation of specific associations, then it follows that direct manipulation of experience will produce an adult learning system that is structured atypically.

Sullivan (1979) examined these notions within the paradigmatic case of structured or constrained learning. She attempted to make visual cues relevant and taste cues, at best. less relevant to the consequences of ingesting a given food in laboratory rats. She did this by using two liquid foods that were similar in taste, odor, and appearance, but differed in ingestional consequences. Two artificial flavors and two distinct visual cues were used as well. The visual cues were made relevant - that is. they were associated consistently with one type of food, and thus with one type of ingestional consequences. In contrast, the taste cues were made irrelevant-they were occasionally placed in food of one type, occasionally in the other. After extensive experience with this procedure, which began at weaning and continued for 37 consecutive days. the rats were tested using a typical conditioned taste-aversion design. In such experiments when a visual cue is paired with illness, little or no detectable learning typically occurs. When a compound stimulus composed of a visual and a taste cue is paired with illness, associations appear to be limited to the taste and to the illness (see. e.g., Garcia \& KLoelling, 1966; LoLordo, 1979). In contrast to the pattern generated with most laboratory rats, Sullivan's aberrantly reared rats learned a conditional aversion to the visual cues alone; more important, the visual cues overshadowed the taste cues when the two were presented in a compound. The learning system of these animals was aberrantly constrained, directly reflecting their unusual early experiences. From this we may conclude that early experience is capable of at least partially laying the basis for a distinction between "prepared" and "unprepared" associations. (For evidence compatible with this assertion, see Bronstein \&Crockett, 1976:Capretta, 1977; Dalrymple \& Galef, 1981: Galef, 1977, 1979; Galef \& dark, 1971, 1972; Galef \& Henderson, 1972; Galef \& Sherry, 1973; Lavin, Freise, \& Coombes, 1980: Warren \& Pfaffman, 1959.)

This analysis suggests that attempts to characterize the structure of adult learning exclusively in terms of genetically given constraints may not adequately capture the flexibility inherent in learning. Although development is without doubt highly canalized (Waddington, 1956, 1957) and normally follows a speciestypical trajectory, one still cannot ignore the contributions of experience. An organism is capable of learning the relation between stimulus classes, and this experience influences the rate at which subsequent associations are formed between these classes. This suggests that experience makes some contribution to the structured nature of learning commonly observed in adult organisms. Commonalities in this early experience are more or less guaranteed by the restricted range of environments to which the young are exposed. These include species-typical parenting patterns and social experiences that may include exposure to diet. protective patterns, and species-typical play routines. Further, at least in humans, speciestypical patterns of exploring objects in the environment (e.g., the in-the-mouth behavior exhibited by almost all human infants) lead to a highly structured experiential base. During infancy, the organism is exposed to signals for danger, safety, food, liquids, conspecifics. manipulable objects, and to a large number of signals that are irrevelant to any of its basic needs. Common stimulus classes could be learned during tnis period and the relevance of these classes to one another determined. Such early learning may help to account for both the selectivity of associative learning and the nonrandom distribution of phobias found in the adult population.

With these facts in mind, we propose that locale learning does not occur independently oftax on learning in the adult. Rather, the content of locale representations, which captures the causal texture of the environment, is determined by laxon based circuitry and by the 
experiences that prepare these circuits. Prepared circuits can be fully potentiated at some later time. Under stress this may translate into the reinstatement of some early-acquired, and long-forgotten, fear. In this way our model accepts the tyranny of childhood.

\section{Extinction and Taxon Systems: Steps \\ Toward Possible Treatment Modalities}

Earlier we focused on several key features of phobias and other fears. These features reminded us of the kind of learning one sees in neonates. with the important exception that phobias are long retained, whereas infant learning appears to be easily lost. Our analysis suggests that the structuring of an organism's associative networks could occur largely during early experiences that are reflected only in changed circuitry-no conscious memory of the events leading to these changes exists. This follows from the proposed role of the hippocampus in the formation of event-specific, context-dependent memories and from the fact that this neural region is not fully functional until at least several years after birth in humans. Our model of the development of phobias thus relies on events that occur both during ontogeny and during adult life-across a boundary denned by the onset of function of a neural system concerned with memory for environmental contexts and the representation of what occurs within these contexts. The formation of phobias - context free. easily generalized, and difficult to extinguish-requires a return to the prehippocampal state. This is accomplished through stress. The contribution of early experience, the critical contribution that defines the nature of the phobic reaction, concerns changes in circuits relating to specific conditional and unconditional stimulichanges that prepare these circuits for reinstatement should they be conjoined with adequate stress ${ }^{10}$ and appropriate environmental conditions some time in the organism's future.

The model in its present form provides a neurobiological perspective within which certain psychopathological phenomena-phobic reactions in particular - can be viewed. That this model more or less adequately accounts for what is currently known about these phenomena is not surprising inasmuch as it was formulated with these features in mind.
Nonetheless, another area remains to be explored. In particular, what does the model say about the ways in which learning within taxon circuits can be undone, or overcome?

Unfortunately, little is known about the process of extinction and/or counterconditioning in normal taxon systems because of complications in interpreting the lesion data (see Footnote 4). Nonetheless, the data do suggest that taxon control is characterized by stereotyped, repetitive, and persistent behavior (O'Keefe \& Nadel, 1978). We infer that pure taxon controlled learning (e.g., conditional fears formed during infancy) should be highly stereotyped and quite resistant to extinction. In contrast, learning within the. locale system (e.g., conditional fears formed during adulthood) should be quite labile, extinguishing quickly. The interaction between these two systems produces the extinction characteristics seen in the laboratory and clinic.

Although there is a tendency to consider extinction as a unitary phenomenon, from the present point of view it is not. We suspect that extinction consists of ai least three separable processes: Changes in memory for the conditional and unconditional stimuli, the appearance of new learning controlled primarily within the locale system, and the weakening of associative bonds. During normal extinction trials, the intact organism may simply, through the locale system, learn that "in this place, the cue no longer has biological meaning." Such learning, controlled through the relatively labile, but behaviorally prepotent, locale system could serve to protect taxon circuits (including associations acquired during infancy) from extinction." If the conditioned stimulus is presented in a new location, such protected taxon knowledge may manifest itself.

We cannot exhaustively review the converg-

\footnotetext{
${ }^{10}$ Memories for events lhat occur during this period will be hazy or nonexistent Those events will however, exert a powerful local control of behavior. For all intents and purposes, taxon control will lead to a regression to earlier, more stereotyped emotional and behavioral patterns (see Altman. Brunner. \& Bayer. 1973). Here we expect the appearance of at least some infantile dependency reactions (e-g., transference neurosis), stereotyped, and repetitive (obsessive-compulsive) behavioral patterns.

" This notion is closely related to the partial irrewrsibitity concept offered by Solomon and Wynne (1954; see also Sollysik. Wolfe, Nicholas, Wilson, \& Garcia-Sanchcz, 1983).
} 
ing evidence consistent with the notion that in intact adults extinction procedures do not entirely eliminate excitatory associative bonds (see Mackintosh, 1974); rather we direct attention to several important findings. First, there are Pavlov's (1927) well-known demonstrations of spontaneous recovery and disinhibition. Following extinction, a period of rest often results in the reappearance of conditional responding. In addition, introducing a novel stimulus - one that elicits an orienting reflexin conjunction with an extinguished conditional stimulus results in the reappearance of the conditional response even after prolonged extinction trials. Second, Reberg (1972) demonstrated that an "extinguished" conditional fear stimulus shows strong residual conditional fear when tested in conjunction with another excitatory stimulus (see also Hendry, 1982). Third, Rescoria and Heth (1975) have shown that extinction that occurs when the unconditional stimulus is simply removed from the conditioning environment may be partially due to a decrease in the strength of the event memory of the original unconditional stimulus. Simply re-presenting the unconditional stimulus following prolonged extinction trials serves as a reminder cue. causing the originally learned conditional fear to once again appear. In a related series of studies, Bouton \& Bolles (1979a) have shown that this reappearance (following extinction)' of conditional fear is specific to the context in which the reminder cues are presented (see also Bouton \& King, 1983). ${ }^{12}$ Fourth. Frey and Butler (1977) have shown that following a conventional extinction procedure, a conditional response is reacquired more quickly than during original acquisition; there appears to be some savings after extinction (see also'Hochler, Kirschenbaum, \& Leonard, 1973; Konorski, 1972; Konorski \& Swedjkowska, 1950. 1952a, 1952b, 1956).

Taken together, these studies point to the fact that extinction procedures rarely, if ever, completely eliminate the effects of excitatory classical conditioning. In typical extinction procedures, associative bonds may be weakened somewhat, but a decrement in conditional responding is controlled by other nonassociative factors. ${ }^{13}$

Most important to us is the demonstration that traditional extinction procedures that involve only the presentation of the.'conditional stimulus are context specific. Bouton and Bolles (1979b) have shown that following prolonged extinction trials in a context different from that in which conditioning occurred, returning the rat to the original context, or to a new context, results in a renewed behavioral manifestation of the conditional fear (see also Archer, Sjoden, Nilsson, \& Carter, 1979, 1980; Cunningham, 1981; Welker \& McAuley, 1978). Bouton (1982a) has shown that this context specificity of extinction results neither from differential levels of contextual fear nor from any conditional inhibition that might accrue during extinction trials. Theoretically this irnplies that the organism discriminates contexts quite well, and based on this discrimination, leams that in a particular place, the conditional response is not appropriate. In a new place the conditional fear manifests itself once again.

\section{Two Implications}

Thus far we have outlined bits and pieces of information taken from several apparently diverse fields of neurobiological inquiry and attempted to place them within a single theoretical framework. In so doing we have arrived at conclusions that are compatible with aspects ofpsychodynamic theory: The critical importance of childhood experience, the difference between two types of learning and memory formation, and perhaps even the role of stress

\footnotetext{
${ }^{12}$ Although there is some disagreement over the mechanism of this reappearance, the point remains the same; even after conditional responding has disappeared, it is rather easily recovered without further pairing of the conditional and the unconditional stimuli.

${ }^{13}$ There is strong evidence that extinction is prolonged in an interesting way when the contiguous temporal relation between the conditional and the unconditional stimuli is simply broken. In addition. Frey and Butler (1977) found that a conditional response is reacquired more quickly following aconventional extinction procedure than following an extinction procedure during which the conditional and the unconditional stimuli have been presented randomly in time. Further, acquisition and reacquisilion curves of the conditional response are quite similar following unpaired presentations of the conditional and the unconditional stimuli. It is as yet unknown if this method of extinction results in laxon (context independent) or locale (context dependent) elimination of the conditional response. Further, we do not know if inflation or reinstatement effects will be found under these circumstances (see Ayres \& DeCosla. 1971; Boakes, 1973: Jacobs, Harris, \& Moot. 1983; Leonard, 1975: Rescoria \& Skucy, 1969).
} 
in setting the stage for therapeutic change (discussed later in this article). Other aspects of our conclusions are compatible with current behavioral, cognitive behavioral, and social learning theories (e.g., the use of desensitization, participant modeling, and direct training programs as therapeutic tools).

It is important to emphasize that we have not presented a general developmental theory within this framework, rather we have considered only a small part of the overall picture, focusing upon ideas necessary to explain the development of certain commonly encountered psychopathologies. To achieve this explanation we have pointed to the late development of the hippocampal formation in humans and other mammals and to the correlation between this development and the lifting of inf antile amnesia. We have suggested that any learning that occurs during this amnesic period exhibits characteristics unique to taxon learning systems. Important among these taxon characteristics are that learning is context independent, generalization is unusually broad, and" extinction ii prolonged and context independent (see 0'K.eefe \& Nadel, 1978). In addition, we have noted that direct behavioral control by the taxon systems seems to disappear as the locale system matures. These characteristics place taxon learning in the unique position of providing the raw materials with which later developing neural structures, designed to analyze the causal texture of the extant environment, can work. Further, we have noted that normally buried (fl.w/2-based behavioral control may be reinstated in the adult under certain hormonal and environmental conditions. This, we suggest, is due to the hormonal disruption of ongoing -htppocampal function: The organism is (partially) returned to the infantile state. We have, throughout, pointed to the similarities between the known characteristics oftaxon-based control and those characteristics that seem to typify human phobias. Finally, we have outlined several notions about the removal of taxonbased conditional fears. Our message here is straightforward: Taxon-based conditional fear might never be eliminated using traditional extinction or counterconditioning procedures. These fears are easily recovered even after extensive exposure to extinction procedures. This, we assert, is partially due to the sluggish nature of the taxon systems and partially due to shielding exerted by a fully functional locale system.

All of this has implications for current treatment modalities and the development of new therapeutic techniques. The fact that conditional fears, once acquired, may never be eliminated, suggests that when we use procedures based on behavioral, cognitive-behavioral, or social learning theory to eliminate phobic reactions, the original associative linkage may be partially broken, yet may still exist in the form ofprepared neural circuits. A client treated in this way is still potentiated or predisposed toward psychopathological reactions if certain environmental events are encountered. The model that we are outlining suggests that even when presenting problems are brought under control, the therapist's job is not complete. At a minimum the therapist must provide additional training for the client, most specifically, training designed to aid in the management of environmentally induced stress.

Our model suggests that any extinction or counterconditioning procedures that are carried out in a given place (e.g.. in an office setting) may not generalize to the home, or the office, or the day-to-day settings that the client encounters. Thus. it may be necessary to provide extinction experience in many different settings in order to achieve the generality that is needed in effective psychotherapy (see, e.g., Goldstein \& Kanfer. 1979). Further, it may be beneficial to continue extinction trials long after the presenting problem is no longer in evidence. If. as we have suggested, the locale system partially protects taxon circuits from extinction, continued presentations of the feared objects or circumstances may serve to decrease the likelihood ofreacquisition of the response.

Although we are quite hesitant to point this out, there is a second, thoroughly unpleasant implication of the present analysis. It suggests that "deep therapy" cannot be accomplished without the use of long-term stress. We have argued that taxon systems are quite sluggish and are, in addition, protected by the presence of a fully functional locale system. Some changes could occur in the taxon systems in the intact, unstressed client, but those changes may require a large time investment, involving repeated presentations of the feared stimulus 
in many different contexts. The change in contexts serves to re-expose taxon systems to environmental contact. An alternative is to gain direct access to the taxon systems; this may be done through the use of drugs or environmentally induced stress. In this state, according to our model, the locale system will be disrupted, while certain of the taxon systems are sensitized. It is unclear what effect traditional extinction or counterconditioning procedures will have under these conditions. The clinical evidence suggests that under stress the strength of a conditional fear will, at least initially, increase dramatically. We suggest that this will occur until full reinstatement has been obtained, at which point extinction of the fear might begin. This sequence closely parallels the pattern of phobic extinction seen in clients undergoing implosive therapies (e.g., Rachman \& Hodgson, 1980; Stampfl \& Leyis. 1976; Wolpe, 1973). Nevertheless, it is unclear exactly to what extent the breaking of associative bonds or decreases in event memories govern the subjective experience of extinction under these circumstances. At a minimum we expect extinction or counterconditioning procedures based upon this principle to be relatively rapid (due to increases in taxon sensitivity) and context free (due to hippocampal disruption). ${ }^{14}$

We are not advocating that this program be implemented; we are. however, arguing that the clinician must pay attention to its roots. Source amnesia, triggering by stress, context independence, broad generalization, persistence. and resistance to cognitive influence characterize most phobic states, yet find no ready explanation in traditional learning-based models. These characteristics derive naturally from a model that takes into account the separate maturation of different learning systems. In addition, our model suggests that current behaviorally based therapies could produce changes that are easily reversed under commonly encountered environmental conditions. It suggests that the clinician's job is not finished when problems have apparently been brought under control. The model suggests several techniques that might prevent such reversals, for example, extended treatment in multiple environments, the addition of stress-management training, or even the careful use of stress during therapy.

Perhaps the real power of the present model lies in its potential to facilitate the construction of an adequate animal model of some forms of human psychopathology. Too little is currently known about the characteristics of extinction under stress, the brain systems that may be the substrate for taxon function, hormonal involvement in the locale and taxon systems, the effects of counterconditioning, and the newly opened area of context specificity. The promissory note that we now write offers only a little in terms of immediate applicability; instead it seeks ways to adequately model, to discover the rules that govern deeply puzzling human problems.

${ }^{14}$ Indeed, crude forms of this type of "therapy" seem to be already in place (e.g., marine bootcamp, police training, hell week in fraternities, moonie indoctrination, the initial experiences found upon entering a prison population, reprograminers. and in some cases, graduate education). Each seems to employ the same basic procedure, stress the organism severely, and then put it through a highly structured program. The similarity of the outcome of these programs is remarkable.

\section{References}

Adams, C., \& Dickinson. A. (1981). Variations in associative representations during instrumental learning. In N. E. Spear \& R. R. Miller (Eds.), Information processing in animals (pp. 143-165). Hillsdale, NJ: Eribaum.

Altman, J., Brunner, R. L.. \& Bayer, S. A. (1973). The hippocampus and behavioral maturation. Behavioral Biology S. 557-596.

Archer.. t., Sjoden, P.-O.. \& Nilsson, L.-G. (1985). Contextual control of taste-aversion conditioning and extinction. In P. D. Balsam \& A. Tomie (Eds.), Context and learning (pp. 225-271). Hillsdale, NJ: Eribaum.

Archer, T, Sjoden, P.-O., Nilsson, L.-G.. \& Carter. N. (1979). Role of exieroceptive background context in taste-aversion conditioning and extinction. Animal Learning and Behavior, 7, 17-22.

Archer. T. Sjoden. P.-O.. Nilsson, L.-G., \& Carter, N. (1980). Exieroceptive context in taste-aversion conditioning and extinction: Odour, cage. and bottle stimuli. Quarterly Journal of Experimental Psychology, 32. 197-214.

Ayres. J.J. B., \& DeCosta, M. J. (1971). The truly random control as an extinction procedure. Pswhonomic Science, 24, 31-33.

Bachevalier, J., \& Mishkin, M: (1984). An early and a late developing system for learning and retention in infant monkeys. Behavioral Neuroscience, 98. 770-778.

Baker. A. G. (1976). Learned irrelevance and learned helplessness: Rats leam that stimuli, reinforcers, and responses are uncorrelaled. Journal of Experimental Psychology: Animal Behavior Processes. 2. 130-141.

Baker. A. G., \& Mackintosh, N. J. (1977). Excitatory and inhibitory conditioning following uncorrelated presentations ofCS and UCS. Animal Learning and Behavior, 5.315-319.

Baker, A. G., \& Mackintosh, N. J. (1979). Preexposure to 
the CS alone, US alone, or CS and US uncorrelaled: Latent inhibition, blocking by context, or learned irrelevance. Learning and Motivation, 10, 279-294.

Balaz, M. A., Capra, S., Hartl. P., \& Miller, R. R. (1981). Contextual potentiation of acquired behavior after devaluing direct context-US associations. Learning and Motivation. 12, 383-397.

Balaz, M. A., Capra, S., Kasprow, W. J., \& Miller, R. R. (1982). Latent inhibition of the conditioning context: Further evidence of contextual potentiation of retrieval in the absence of appreciable context-US, associations. Animal Learning and Behavior, 10, 242-248.

Balsam, P. D., ASchwanz, A. L. (1981). Rapid contextual conditioning in autoshaplng. Journal of Experimental Psychology: Animal Behavior Processes, 7, 382-393.

Balsam, P. D., \& Tomie. A. (1985). Context and learning. Hillsdale, NJ: Eribaum.

Bandura.A. (1977). Social learning theory. Prentice-Hall: Engelwood Cliffs, NJ.

Bemn, A. E (1963). The effects of psychotherapy: Negative results revisited. Journal of Counseling Pswhologv, JO. 244-250.

Bergson, H. (1896). Matters el Memoirs (Matter and memory]. Paris: Alcan.

Berk. A. M., Vigorito, M., \& Miller, R- R. (1979). Retroactive stimulus interference with conditioned emotional response retention in infant and adult rats: Implications for infantile amnesia. Journal a/Experimental Psychology: Animal Behavior Processes. 5, 284-299.

Black, A. H. (1959). Heart rate changes during avoidance learning in dogs. Canadian Journal of Psychology. 13. 229-242.

Blakemore, C. (1974). Developmental factors in the formation of feature extracting neurons. In F. 0. Schrnitt iS: F. G. Worden (Eds.), The neurosciences third study program. Cambridge, MA: MIT Press.

Bcakes, R. A. (1973). Response-independent decrements produced by extinction and by response-independent reinforcement. Journal of the Experimental Analysis of Behavior, 19, 293-302.

Bouton, M. E. (1982a). Conditioned fear and the associative value of the context. Paper presented at the meeting of the Psychonomic Society, Minneapolis, MN.

Bouton. M. E. (1982b). Lack of reinstatement of an extinguished taste aversion. Animal Learning and Behavior, 10. 233-241.

Bouton, M. E. (1984). Differential control by context in the inflation and reinstatement paradigms. Journal of Experimental Psychology. Animal Behavior Processes. 10. $56-74$.

Bouion, M. E., \& Bolles. R. C. (1979a). Contextual control of extinction of conditioned fear. Learning and Motivation, 10, 445-466.

Bouion. M. E., \& Bolles, R. C. (1979b). Role of conditioned contextual stimuli in reinstatement of conditioned fear. Journal of Experimental Psychology: Animal Behavior Processes, 5, 368-378.

Bouion, M. E., \& King. D. A. (1983). The contextual control of extinction of conditioned fear. Tests for the associative value of the context. Journal of Experimental Psychology: Animal Behavior Processes, 9, 248-265.

Breger, L., \& McGaugh. J. (1965). Critique and reformulation of "learning theory" approaches to psychotherapy and neurosis. Psychological Bulletin, 63. 338358.

Bronsiein, P. M., \& Crockett. D. P. (1976). Maternal rations affect the food preferences of weanling rats: III. Bulletin of the Psychonomic Society. S. 227-229.

Campbell, B. A., \& Campbeli, E. H. (1962). Retention and extinction oflearned fear in infants and adult rats. Journal of Comparative and Physiological Psychology. 55, $1-8$.

Campbell, B. A., \& Jaynes, J. (1966). Reinstatement. Psychological Kevie'r. 73. 478-480.

Campbell, B. A., \& Spear, N. E. (1972). Ontogeny of memory. Psychological Reviw. 79, 215-236.

Capreita, P. J..(!977). Establishment of food preferences by exposure to ingestive stimuli early in life. In L. M. Barker, M. R. Best, \& M. Domjan (Eds.) Learning mechanisms in food selection (pp. 99-121). Waco, TX: Bavlor University Press.

Cloplon, J. P., \& Winfield. J. P. (1976). Effect of early exposure to patterned sound on unit activity in rat inferior colliculus. Journal of Heuroscience, 39. 10811089.

Cohen, N. J., \& Squire, L. R. (1980). Preserved learning and retention of pattern analyzing skill in amnesia: Dissociation of knowing how and knowing that. Science, 210. 207-209.

Coulter, X., Collier, A. C., \& Campbell, B. A. (1976). Longterm retention of early Pavlovian fear conditioning in rats. Journal of Experimental Psychology: Animal Behavior Processes. 2. 4S-56.

Cunningham, C. L. (1981). Association between the elements of a bivalent compound stimulus. Journal of Experimental Psychology: Animal Behavior Processes. 7, 425-436.

Dalrymple, A. J., \& Galef, B. G. Jr. (1981). Visual discrimination preiraining facilitates subsequent visual cue/ toxicosis conditioning in rats. Bulletin of the Psychonomic Society, 18. 267-270.

Delprato, D. J. (1980). Hereditary determinants of fears and phobias: A critical review. Behavior Therapy, 11 , 79-103.

DeSilva, P., Rachman, S., \& Seligman, M. E. P. (1977). Prepared phobias and obsessions: Therapeutic outcome. Behaviour Research and Therapy. 15, 65-77.

Devenport, L. D., \& Holloway, F. A. (1980). The rats resistance to superstition: Role of the hippocampus. Journal of Comparative and Physiological Psychology, 94, 691-705.

Dollard, J., \& Miller, N. E. (1950). Personality and psychotherapy. New York: McGraw Hill.

Domjan, M., \& Galef, B. G., Jr. (1983). Constraints on instrumental classical conditioning: Retrospect and prospect. Animal Learning andBehavior. 11, 151-161.

Dudycha, G-, \& Dudycha, M. (1941). Childhood memories: A review of the literature. Pswhological Bulletin, 38. 668-682.

Dweck, C. S., \& Wagner. A. R. (1970). Situational cues and correlation between CS and US as determinants of the conditioned emotional response. Psvchonomic Science. IS. 145-147.

Eysenck, H. J. (1976). The learning theory model of neurosis-A new approach. Behaviour Research and Therapy, 14.25\-267.

Eysenck, H. J. (1979). The conditioning model of neurosis. Behavioral and Brain Sciences, 3. 155-199.

Eysenck, H. J. (1981). Behavior therapy and the conditioning model of neurosis. International Journal of Psychology. 16. 343-370.

Force, D. D., \& LoLordo, V. M. (1973). Attention in the 
pigeon: Differential effects of food-getting versus shock avoidance procedures. Journal of Comparative and Physiological Psychology. 85, 551-558.

Force, D. D., \& LoLordo, V. M. (1975). Stimulus-reinforcer interactions in the pigeon: The role of electric shock and the avoidance contingency. Journal of Experimental Psychology: Animal Behavior Processes, !, 39-46.

Fredrikson, M., Hugdahl, K.., \& Ohman, A. (1977). Electrodcrmal conditioning to potentially phobic stimuli in male and female subjects. Biological Psychology, 4, 305314.

Freud, S. (1895). A reply to criticisms on the anxiety neurosis. Collected works (Vol. 1). London: Hogarth Press.

Frey, P. W., \& Butler, C. S. (1977). Extinction after associative conditioning: An associative or nonassociative process? Learning and Motivation. 8, 1-17.

Galef, B. G.. Jr. (1977). Mechanisms for the social transmission of food preferences from adult to weanling rats. In L. M. Barker, M. R. Best, \& M. Domjan (Eds.), Learning mechanisms in food selection (pp. 123-148). Waco, TX: Bayior University Press.

Galef, B. G., Jr. (1979). Social transmission of learned diet preferences in wild rats. In J. H. A. Kroeze (Ed.), Preference behavior and chemorecepiion (pp. 411-431). London: Information Retrieval.

Galef, B. G., Jr., \& Clark, M. M. (1971). Social factors in the poison avoidance and feeding behavior of wild and domestic rat pups. Journal of Comparative and Physiological Psychology, 75. 341-357.

Galef, B. G., Jr., \& Clark, M. M. (1972). Mother's milk and adult preference: Two factors determining initial dietary selection by weaning rats. Journal of Comparative and Physiological Psychology. 78. 220-225.

Galef, B.'G., Jr., \& Dalrymple, A. J. (1981). Toxicosisbased aversions to visual cues in rats: A lest of the Testa and Teroes hypothesis. Animal Learning and Behavior, 9, 332-334.

Galef, B. G., Jr., \& Henderson, P. W. (1972). Mother's milk: A determinant of the feeding preferences and weanling rat pups. Journal of Comparative and Physiological Psyvhologv. 78, 213-219.

Galef, B. G., Jr., \& Sherry, D. F. (1973). Mothers milk: A medium for the transmission of cues reflecting the flavor of mothers milk. Journal of Comparative and Physiological Psychology. 83. 374-378.

Garcia, J-, \& Koelling, R. A. (1966). Relation of cue to consequence in avoidance learning. Pswhonomic Science, 4, 123-124.

Geer, J. H. (1965). The development of a scale to measure fear. Behavioural Research and Therapy, 3. 45-53.

Gibson, J. J., \& Gibson, E. J. (1955). Perceptual learning: Differentiation or enrichment? Pswhological Revie $v$, 62, 32-41.

Goldstein, A. P., \& Kanfer, F. H. (Eds.) (1979). Maximizing treatment gains: Transfer enhancement in psychotherapy. New York: Academic Press.

Gordon, W. C., McCracken, K. M., Dess-Beech, N., \& Mowrer, R. (1981). Mechanisms for cueing phenomenon: The addition of the cueing context? Learning and Motivation, 12. 196-211.

Gotllieb, G. (1976). The role of experience in the development of behavior and the nervous system. In G. Gotllieb (Ed.), Development of neural and behavioral spec- tficily (pp. 25-54). New York: Academic Press.

Grant, D. A. (1973). Cognitive factors in eye-lid conditioning. Psyclwphysiology. 10. 75-81.
Grings, W. W. (1973). Cognitive factors in eleclrodermal conditioning. Psychological Bulletin, 79, 200-210.

Harlow, H. F., \& Mean, C. (1979). The human model: Primate perspectives. New York: Wiley.

Haroutunian, V., \& Riccio, D. C. (1977). Effect ofarousal conditions during reinstatement treatment upon learned fear in young rats. Developmental Psvchobiology, 10, 2532.

Haroutunian, V., \& Riccio, D. C. (1979a). Age-dependent effects of preconditioning aversive experiences on the retention of conditioned fear in weanling rats. Behavioral and Neural Biology. 26. 248-253.

Haroutunian, V., \& Riccio. D. C. (1979b). Drug-induced "arousal" and the effectiveness of CS exposure in the reinstatement of memory. Behavioral and Neural Biology. 26. 115-120.

Hendry, J. S. (1982). Summation of undetected excitation following extinction of the CER. Animal Learning and Behavior, 10, 476-482.

Hochler, F. K., Kirschenbaum, D. S., \& Leonard, D. W. (1973). The effects of overtraining and successive extinctions upon nictitating membrane conditioning in the rabbit. Learning and Motivation, ^.91-101.

Holland, P. C. (1977). Conditioned stimulus as a determinant of the form of the conditioned response. Journal of Experimental Pswiuslogv: Animal Behavior Processes. 3. 77-104.

Holland, P. C-, \& Rescorla. R. A. (1975). The effect of two ways of devaluing the unconditioned stimulus after firsiand second-order appetiiive conditioning. Journal of Experimental Pswiiologv: Animal Behavior Processes, 1.355-363.

Holland, P. C., \& Straub. J. J. (1979). Differential effects of two ways of devaluing the unconditioned stimulus after Pavlovian appelilive conditioning. Journal of Experimental Psychology: Animal Behavior Processes. 5. 65-78.

Hubel, D. H., \& Wiesel, T. N. (1965). Binocular interaction in striale cortex of kittens raised with artificial squint. Journal of Neurophysiolos $\backslash:$ 28, 1041-1059.

Hugdahl, K., Fredrikson, M., \& Ohman. A. (1977). "Preparedness" and "arousability" as determinants ofelectrodermal conditioning. Behaviour Research and Timapy, 15, 345-353.

Hugdahl. K., \& Ohman, A. (1977). Effects of instruction on acquisition and extinction ofelectrodennal responses to fear relevant stimuli. Journal of Experimental Psychology: Human Learning and Memory. 3. 608-618.

Jacobs, W. J., Harris, C., \& Moot, S. A. (1983). The role of a feedback stimulus in extinction of an avoidance response. Canadian Journal of Psychology, 37, 557-564.

Jacobs, W. J., \& LoLordo, V. M. (1977). The sensory basis of avoidance responding in the rat: Relative dominance of auditory or visual warning signals or safety signals. Learning and Motivation. S, 448-466.

Jacobs, W. J., \& LoLordo, V. M. (1980). Constraints on Pavlovian aversive conditioning: Implications for avoidance learning in the rat. Learning and Motivation, I I , 427-455.

Jacobs, W. J., Zeilner, D. A., Riley, A. L., \& LoLordo, V. M, (1981). The effects of post-conditioning exposure to morphine in the retention of morphine-induced conditioned-tasteaversion. Pharmacology, Biochemistry, and Behavior. 14. 779-784.

Kamin. L. J., Brimer, C. J., \& Black, A. H. (1963). Conditioned suppression as a monitor of fear of the CS in 
the course of avoidance training. Journal of Comparative and Physiological Psychology. 56. 497-501.

Konorski, J. (1972). Some ideas concerning physiological mechanisms of so-called internal inhibition. In R. A. Boakes \& M. S. Halliday (Eds.), Inhibition and learning. New York: Academic Press.

Konorski, J., \& Szwejkowska, G. (1950). Chronic extinction and restoration and conditioned reflexes: I. Extinction against an excitatory background. Ada Biologiae Experimentalis. 15. 155-170.

Konorski, ]., \& Szwejkowska, G. (1952a). Chronic extinction and restoration of conditioned reflexes: III. Defensive motor reflexes. Ada-Biologiae Experimentatis. 16. 91-94.

Konorski, J., \& Szwejkowska, G. (19520). Chronic extinction of restoration of conditioned reflexes: IV. Dependence of the course of extinction and restoration of conditioned reflexes on the "history" of the conditioned stimulus (the principle of the primacy of first training). Ada Biologiae Experimentalis. 16, 95-113.

Konorski, J., \& Szwejkowska. G. (1956). Reciprocal transformations of heterogeneous conditioned reflexes. Ada Biologiae Experimenialis. 17. 141-165.

Krane, R. V., \& Wagner, A. R. (1975). Taste aversion learning with a delayed shock US: Implications for the "generality of the laws of learning." Journal of Comparative and Physiological Psychology. 88. S82-889.

Kremer, E. F. (1971). Truly random and traditional control procedures in CER conditioning in the rat. Journal of Comparative and Physiological Psychology. 76.441-448.

Landy. F. J., \& Gaupp. L. A. (1971). A factor analysis of the fear survey schedule III. Behaviour Research and Therapy 9. 89-93.

Lavin. M. J., Freise, B., \& Coombes, S. (1980). Transferred flavor aversions in adult rats. Behavioral and Neural Biology. 28. 15-33.

Lawlis, G. F. (1971). Response styles of a patient population on the fear schedule. Behaviour Research and Therapv, 9. 95-102.

Lazarus, A. A. (1971). Behavior therapv and bevond. New York: McGraw-Hill.

Leonard, D. W. (1975). Partial reinforcement effects in classical aversive conditioning in rabbits and human beings. Journal of Comparative and Physiological Psychology. 88, 596-608.

Linden, 5. R. (1969). Attenuation and reestablishment of the CER by discriminated avoidance conditioning in rats. Journal of Comparative and Physiological Psychology, 69. 573-578.

Locke. E. A. (1971). Is "behavior therapy" behavioristic? Psychological Bulletin. 76.318-327.

LoLordo, V. M. (1979). Selective associations. In A. Dickinson \& R. A. Boakes (Eds.), Mechanisms of learning and motivation: .4 memorial to Jerzy Konorski (pp. 367398). Hillsdale, NJ: Eribaum.

LoLordo, V. M., \& Jacobs, W. J. (1983). Constraints on aversive conditioning in the rat: Some theoretical considerations. In P. Harzan \& M. Zeiler (Eds.), Advances in the analysis of behavior (pp. 325-350). London: Wiley.

LoLordo, V. M., Jacobs, W. J., \& Force, D. D. (1982). Failure to block control by a relevant stimulus. Animal Learning and Behavior. 10, 183-193.

Lorenz, K_ Z. (1981). The foundations of ethology. New York: Springer-Verlag.

Mackintosh, N. J. (1973). Stimulus selection: Learning to ignore stimuli that predict no change in reinforcement. In R. A. Hinde \& J. S. Slevenson-Hinde (Eds.), Con- straints on learning: Limitations and predispositions (pp. 75-100). Cambridge. England: Academic Press.

Mackintosh, N.J.(1974). The psychologyoflearning. New York: Academic Press.

Mackintosh, N. J. (1983). Conditioning and associative learning. Oxford University Press: New York.

Marks, I. M. (1969). Fears and phobias. New York: Academic Press.

Marler, P. (1970). A comparative approach to vocal learning: Song development in white-crowned sparrows. Journal of Comparative and Physiological Psychology Monograph 71 (2, Pi. 2).

Marler, P. (1977). Sensory templates, vocal perception, and development: A comparative view. In M. Lewis \& L. A. Rosenblum (Eds,), Interaction, conversation, and the development oflanguage (pp. 95-114). New York: Wilev.

Marler, P., Mundinger. P., Waser, M. S., \& Lunon. A. (1972). Effects of acoustical deprivation on song development in the redwing blackbird. Animal Behaviour, 20. 586606.

Marler, P., \& Peters, S. (19S1). Birdsong and speech: Evidence for special processing. In P. Eimus \& J. Miller (Eds.), Perspectives on the snidv of'speech (pp. 75-112), Hillsdale. NJ: Eribaum.

Marlin, N. A. (1981). Contextual associations in trace conditionine. Animal Learning and Behavior, 9, 519523.

Marlin, N. A. (1982). Within-compound associations between the context and the conditioned stimulus. Learning and Motivation. 13. 526-541.

McCormick. D. A.. dark. G. A., Lavond. D. G.. \& Thompson, R. F. (1982). Initial localization of the memory trace for a basic form of learning; Proceedings of the National Academy of Sciences USA. 79, 27312742 .

McEwen, B. S. (1982). Glucocorticoids and hippocampus: Receptors in search of a function. In D. Ganten \& D. Pfaff(Eds.). Current topics in neiiroendocriiwlogy (Vol. 11. pp. 23-47). Berlin: Springer-Verlag.

McEwen, B. S., Weiss, J. M., \& Schwartz, L. S. (1969). Uptake of corticosterone by rat brain and its concentration by certain limbic structures. Brain Research, 16. 227-241.

McNally, R. J., \& Reiss. S. (1982). The preparedness theory of phobias and human safety-signal conditioning. Behaviour Research and Therapy. 20. 153-159.

Mednick, S. A., \& Lehtinen, L. E. (1957). Stimulus generalization as a function of age in children. Journal of Experimental Ps $\backslash$ hologv. 53, 180-183.

Micco, D. J., Jr.. McEwen, B. S., \& Shein, W. (1979). Modulation of behavioral inhibition in appetitive extinction following manipulations of adrenal steroids in rais: Implications for involvement of the hippocampus. Journal of Comparative and Physiological Psychology. 93, 323329.

Milner, B. (1966). Amnesia following operation on the temporal lobes. In C. W. M. Whitly \& 0. L. Zangwill (Eds.), Amnesia (pp. 109-133). London: Butlerworth.

Mineka, S. (1979). The role of fear in theories of avoidance learning, flooding, and extinction. Psychological Bulletin. 86. 985-1010.

Mishkin, M., Malamut, B., \& Bachevalier, J. (1984). Memories and habits: Two neural systems. In G. Lynch, J. L. McGaugh, \& N. M. Weinberger, (Ed5.), Neurobiology oflearning and memory (pp. 65-134). New York: Guilford Press.

Miyawaki, K., Strang, W., Verbrugge, R. R., Liberrnan, 
A. M.. Jenkins, J. J..'\& Fujimura. 0. (1975). An cncci of linguistic experience: The discrimination oC(r) and (1) by native speakers of Japanese and English. Perception and Psychophysics. IS. 331-340.

Moscovitch, M. (1984). Infant memory. New York: Plenum.

Nadel, L.. \& Willncr, J. (1980). Context and conditioning: A place for space. PhysiologicalPsychology. 8. 218-228.

Nadcl, L, Willna; J., \&KUTZ, E; M. (1985). Environmental context and cognitive maps. In P. Balsam \& A. Tomic (Eds.), Context and learning (pp. 385-406). Hillsdalc, NJ: Eribaum.

Nadcl, L., \& Zola-Morgan, S. (1984). Infantile amnesia: A neurobiological perspective. In M. Moscovitch (Ed.). Infant memory (pp. 145-172). New York: Plenum.

Odling-Smee, F.J. (1975). The role of background stimuli during Pavlovian conditioning. Quarterly Journal of Experimental Psychology. 27.101-209.

OdIing-Smee, F. J. (1978). The overshadowing of background stimuli by an informative CS in aversivc Pavlovian conditioning with rats. Animal Learning and, Behavior. 6. 43-51.

Qhman, A., Eriksson, A.. \& Olofsson, C. (1975). One-trial learning and superior resistance to extinction ofauionomic responses conditioned to potentially phobic stimuli. Journal of Comparative and Physiological Psv-clwlogy, SS. 619-627.

Ohman. A., Erixon. G.. \& Lofberg. I. (1975). Phobias and preparedness: Phobic versus neutral pictures as conditioned stimuli for human auionomic responses. Journal of Abnormal Psychology: 8-f. 41-45.

Ohman, A., Frcdrikson, M., Hugdahl, K-, \& Rimmo, P. . (1976). The premis ofequipotentiality in human classical conditioning: Conditioned clectrodermal responses to potentially phobic stimuli. Journal of Experimental Psychology: General. 105. 331-337.

O'Keefe, J., \& Nadel, L. (1978). The hippocampus as a cognitive map. London: Oxford University Press.

Pavlov, I. P. (1927). Conditioned reflexes: London: Oxford University Press.

Pfaff. D. W., Silva, M. T. A., \& Wdss, J. (1971). Telemetered recording of hormone effects on hippocampal neurons. Science. 172, 394-395.

Rachman, S. J. (1976). The passing of the two-stage theory of fear and avoidance: Fresh possibilities. Behaviour Research and Therapy. 14. 125-131.

Rachman, S. J. (1977). The conditioning theory of fear acquisition: A critical examination. Behaviour Research and Therapy. 15. 375-387.

Rachman, S. J., \& Hodgson, R. J. (1980). Obsessions and compulsions. New York: Prentice-Hall.

Rachman, S. J., \& Scligman, M. E P. (1976). Unprepared phobias: "Be prepared." Behaviour Research and Therapy. 14. 333-338.

Rachman, S. J., \& Wilson, T. (1980). The effects of psychotherapy. London: Pcrgamon.

Randich, A., \& Haggard, D. (1983). Exposure to the unconditioned stimulus alone: Effects on retention and acquisition of conditioned suppression. Journal ofExperimental Psydiohgy: Animal Behavior Processes. 9. 147159.

Randich, A., \& LoLordo, V. M. (1979). Associative and nonassociative theories of the UCS pre-cxposurc phenomenon: Implications for Pavlovian conditioning. Psychological Bulletin. 86. 523-548.

Rcbcrg, D. (1972). Compound tests for excitation in early acquisition and after prolonged extinction of a condi- tioned suppression. Learning and Motivation. 3, 246258.,.

Regan;'D. M. (1982). Visual information channeling in normal and disordered vision. Psychological Review. S9. 407-444.

Rciff, R...\& Schcerci; M. (1959). Memory and hypnotic age regression: Developmental aspects of cognitive function explored through hypnosis. New 'ybric International University Press.

Rciss, B. F. (1946). Genetic changes in semantic conditioning. Journal of Experimental Psvcliology. 36. 530533.

Rescorla. R. A. (1973); The effect of US habiluation following conditioning. Journal of Comparative and Physiological Psychology. S2. W-\A3.

Rescorla, R. A. (1974). Effect of inflation of the unconditioned stimulus value following conditioning. Journal of Comparative and Physiological Psychology. 86. 101106.

Rescorla, R. A. (1980). Pavlovian second-orderconditioning: Studies in associative learning. Hillsdalc, NJ: Eribaum.

Rescorla- R. A., \& Heih. C. D. (1975). Reinstatement of fear to an extinguished conditioned stimulus. Journal of ExperimentalPsychology: AnimalBehaviorProcesses. 104. 88-96.

Rescorla, R. A., \& Skucy, J. C. (1969). Effect of responseindependent reinforcers during extinction. Journal of Comparative and Physiological Psychology. 67. 381-389.

Rcvusky. S., \&. Parker,L. A. (1976). Aversion to unflavortd water and cup drinking produced by delayed sickness. Journal of Experimental Psychology: Animal Behavior Processes, 2. 342-353.

Riccio, D. C., \& Haroutunian, V. (1979). Some approaches to the alleviation of onlogcneuc memory deficits. In N. E. Spear \& B. A. Campbcll (Eds.), Ontogeny oflearning and memory (pp. 289-309). New York: Eribaum.

Riley. A. L., Jacob's, W. J., \& LoLordo, V. M. (1976). Drug exposure and the acquisition and retention of a conditioned taste aversion. Journal of Comparative and Physiological Pswiiologr. W, 799-807.

Rubin, B. M.,' Katkin, E. S., Weiss, B. W., \& Efran, J. S. (1968). Factor analysis of a fear schedule. Behaviour Research and Therapy. 6. 65-75.

Rudy. J. W., Iwens.'J., \& Best. P. J. (1977). Pairing novel cxtcroceptivc cues and illness reduces illness-induced taste aversions. Journal of Experimental Psychology: Animal Behavior Processes. 3. 14-25.

Rudy, J. W., Rosenburg. L., \& Sandcll. J. H. (1977). Disruption of a taste familiarity effect by novel cxlerocepiivc stimulation. Journal of Experimental Psychology: Animal Behavior Processes. 3, 26-36.

Rylc, G. (1949). Tlie concept ofmind. London: Hutchinson.

Sapolsky. R., Krey, L., \& McEwcn, B. S. (1984). Stress down-regulates conicosteronc receplon in a site specific manner in the brain. Endocrinology, 114, 287-292.

Sarricau. A., Vial. M, Philbert, D., \& Rostene, W. (1984). In vitro auioradiographic localization of'H Conicosieronc binding sites in rat hippocampus. European Journal of Pharmacology, 98. 151-152.

Schaclcr, D. L-, \& Moscovilch, M. (1984). Infants, amnesics, and dissociable memory systems. In M. Moscovitch (Ed.), Infant memory (pp. 173-216). New Yorfc Plenum.

Scligman, M. E. P. (1970). On the generality of the laws of learning. Psychological Review. 77. 406-418.

Scligman, M. E. P. (1971). Phobias and preparedness. Behavior Therapy, 2, 307-320. 